\title{
Examination of Secondary School Seventh Graders' Proof Skills and Proof Schemes
}

\author{
Ceylan Sen ${ }^{1, *}$, Gursel Guler ${ }^{2}$ \\ ${ }^{1}$ Department of Science Education, Faculty of Education, Bozok University, Turkey \\ ${ }^{2}$ Department of Elementary Mathematics Education, Faculty of Education, Bozok University, Turkey
}

Copyright (C) 2015 by authors, all rights reserved. Authors agree that this article remains permanently open access under the terms of the Creative Commons Attribution License 4.0 International License

\begin{abstract}
The aim of this study is to examine current proof making skills of secondary school seventh graders using proof schemes. Data of the study were collected in two phases. Initially, Proof Schemes Test, which was developed by the researchers, was administrated to 250 seventh grade students from eight secondary schools, which were chosen randomly. The answers of the students were classified according to proof schemes defined by Harel and Sowder (1998). In the second phase, semi-structured interviews were made with 9 students whose answers were in different proof schemes. As a result of the study, it was seen that the proofs produced by the students were generally in external and empirical proof schemes. In parallel with this finding, it was concluded that students' proof skills were not at an adequate level.
\end{abstract}

Keywords Mathematical Proof, Proof Scheme, Proof Instruction, Proof at Secondary School Level

\section{Introduction}

Mathematical proof involves following a logical path to explain a hypothesis and explanations of why and how the result is reached based on assumptions [1]. Mathematical proof is produced to show the accuracy of the result with different justifications, inform and persuade others about a certain issue and incorporate the results obtained into a system [2]. Proof is an essential element to develop mathematical understanding and to construct mathematical knowledge [3], [4]. Learners' development of the concept of proof individually involves a cognitive construction, and the concept of proof also as a persuasive argument presented for the acceptance of others constitutes the structure of individual's cognitive development process [5]. The process of mathematical proof was defined by Lee [6] as the investigation of the theorem planned to be proved, arrangement of proof steps and presentation to others. Therefore, it is important to reach the conclusion with correct proof operations for a proof to be valid [7]. However, it is seen that there is not any agreement among researchers with regard to how proof is to be made [8]. This stems from the fact that researchers classify proof methods in different ways [9], [10], [11] and these classifications are mistranslated into Turkish.

\section{Proof Instruction}

Proof is a prominent element in mathematics education as it ensures conceptual and meaningful learning rather than rote learning [12]. In mathematics classes, proof functions as a means for students to develop mathematical understanding and mathematical reasoning [13]. Therefore, proof is to be adapted in all grades and used as a means in an educational process [14]. According to Laborde [15], proof is not only the basis of mathematics but also the essence of doing mathematics. Proof takes an important place in the final reform document issued by NCTM (National Council of Teachers of Mathematics) [16]. In several studies, the importance of proof in school mathematics is emphasized [17], [18], [19], [20]. Traditionally, the implementation of proof at secondary education level starts with a mathematical theorem presented and ends with students' exhibition of realities related to the theorem by producing logical arguments [21]. In its current practice, making proof is regarded as a formal procedure not related to experimental activities. Such kind of a practice and instruction does not give students the impression that mathematical information has an ever-developing dynamic structure [22].

In line with this, Stylianides [22] defines proof as discussion types and developing ideas suitable for the condition. Following from this definition, it is understood that doing proof is an interactive process in which students interact with their instructors [23]. In line with this understanding, through proof activities in classes, students are to be given opportunities to develop their reasoning skills, grasp basic dimensions of mathematics, make mathematical assumptions and justify them through investigation and assess mathematical arguments by means of various proof methods [16]. Alibert and Thomas [24] suggest providing 
educational environments where students convince others by validating or falsifying the propositions they express.

Making mathematics via proof lays the foundation for creating and developing mathematical information [3]. Three important characteristics for making valid proof in class have been defined by Stylianides [22]:

1. Accurate and appropriate statements are accepted by other in class via justification.

2. Majority of the class use reasonable, appropriate and valid conceptualization

3. Appropriate and accurate conceptualization is achieved through communication among people in the classroom.

\section{Proof at Primary School Level}

The integration of students' mathematical experience and the idea of proof at the beginning of education with how proof can be made at early grades raise an important issue in education [25]. To sustain robust development of proof skill, educational programs are to be prepared to be fit for the apprehension of early age children and the level should be increased for higher grades as their cognitive levels increase [16]. Existence of the concept of "proof" in primary school mathematics education program is regarded to be an important issue because in many countries primary school mathematics education focuses on arithmetical concepts, calculations and algorithm; however, Lampert [26], Maher and Martino [27], and Carpenter and Franke [28] argue that children at early ages can understand proof. When children pass to the higher levels of education, they encounter the concept of proof especially in geometry [17]. For a smooth transition between education programs of different levels, it is essential that a connection between these education programs be established [20], [29]. In many studies, it is reported that students who pass from primary level to secondary level education experience difficulties when learning proof and they are inadequate to make explanations for these difficulties [30], [31].

NCTM draws attention to the importance of the development of the concept of proof, reasoning and individual development in the report entitled as "The Principles and Standards of School Mathematics". NCTM [16] lists the following elements for the development of reasoning and proof development in children at early ages:

1. Students must grasp that reasoning and making proof are the essential components of mathematics.

2. They should be able to develop mathematical ideas and experience them.

3. They should be able to develop the proof they form through discussion and communication.

4. They should be able to use proof methods appropriate for the context.

Even if the concept of proof is not given place in primary school mathematics syllabus, reasoning is defined as "the process of obtaining new information using mathematical means (symbols, definitions etc.) and reasoning techniques (induction, deduction, comparison, generalization etc.)" [32].
In this definition, the skill of reasoning is indirectly related with making proof. Teaching elementary school children how to make proof in accordance with their cognitive development level is an important issue. The questions of "What is proof?", "Can proof be made?", "What is the difference between proof and justification?" emerge. In a study by Stylianides and Stylianides [33] which focuses on proof at primary education level, they emphasize that tendency to make generalization at early ages can be called as proof.

With regard to the development of the idea of proof in individuals, Harel and Sowder [29] reveal the cognitive development based on the reasons students show in their proof schemes. As reasoning skills are at the forefront in primary schools pupils, Stylianides and Stylianides [33] argue that these schemes are to be called as "justification schemes" rather than as "proof schemes". They state that these schemes include justifications based on testing with examples and mathematical appearance with physical materials [33]. De Villers [34] states that mathematical proof involves the components of justification, explanation, exploration, systematization, mental challenging and communication, all of which are related to each other. Harel and Sowder [5] state that many proof schemes based on these components tally with each other. Therefore, in this study, proof schemes developed by Harel and Sowder [29] are used because they bear similarities with many proof schemes in the literature [20], [35], [36], [37]. The proof schemes developed by Harel and Sowder [29] are:

External conviction, students perform the proof process via ideas in their minds. In this process, students do not try to develop a new proof. Claims based on rote learning which are developed intuitively or existing in textbooks and transferred by teachers are the examples of such proof making process. It is divided into three categories:

- Authoritarian proof scheme: proof based on student, teacher, book or any other authority.

- Ritual proof scheme: proof is made based on opinion and form not on the content.

- Symbolic proof scheme: student tries to convict through symbolic representations and statements without knowing the meanings of symbols.

Empirical proof is composed of claims students develop based on their intuitions. Empirical proof is divided into two as inductive and perceptional proof. In empirical proof students make claims based on the examples they choose on purpose. The claims made are realized via physical realities or senses and proven with experiments. It is divided into two:

- Inductive proof scheme: students try to convict with examples and trials. Generalization is made with one or several examples.

- Intuitive proof scheme: students try to make proof by making deductions based on perceptional representations.

Analytical proof is the conclusion drawn based on logical 
deductions. It is divided into two as transformational and axiomatic proof schemes. This proof is based on definitions with formal structures. Formal concepts are developed through theoretical definitions not in line with existing ideas. Verification is achieved using axioms and the difference between axiom and theorem is grasped. It is divided into two:

- Transformational proof scheme: mental guesses are made with regard to the accuracy of the proposition and deductions are made based on these guesses. It features generalization, operational thinking and logical deduction.

- Axiomatic proof scheme: proof is made by using axioms and theorems.

In studies on proof at primary school level, the effects of the strategies and media used in class, encouragement by teacher to make proof, generalization and arguments on proof making skill of pupils have been reported [38], [39], [40]. In the literature, it is emphasized that proof is the basic component of mathematics education and children at all ages can make proof when effective teaching methods and techniques are used [27], [41], [42]. In mathematics education, according to Aylar and Şahiner [12], with the integration of proof to the syllabus at early ages, students are taught why and how something happens rather than only being presented accurate information in a ready-made form. In this way, meaningful and conceptual learning, which is the ultimate aim in education, takes place. Development of reasoning for proof starts at early ages and pupils can make justifications. Development of proof skill at early ages enables students to make proofs for various topics in the future [12]. Stylianides and Stylianides [33] state that proof instruction in early age children should not be given formally but according to their cognitive development levels and they are to be given opportunities to make their own justifications. In line with this, the aim of this study is to reveal current proof making status and skills of 7 th grade students according to proof schemes defined by Harel and Sowder [29].

\section{Methodology}

\section{Participants}

The study was carried out with 250 students attending secondary schools in a city in Central Anatolia in the spring term of 2014 and 2015 academic year. While 132 of the participants were female, 118 were male and their mean age was 13. Eight schools included in the study were chosen through lottery from the list of all schools in the city center. The seventh grade students in these eight schools were informed about the aim of the study. After being informed, 250 seventh grade students volunteered to participate the study. Each students who took part in the study were given code names as $\mathrm{S} 1, \mathrm{~S} 2 \ldots, \mathrm{S} 250$.

\section{Data Collection Tool and Analysis}

Six-item Proof Schemes Test (PST), which was developed by the researchers, was used as data collection tool. For the development of PST, the researchers initially examined the proof problems used in the studies in the literature. Later on, the researchers prepared a 10 -item pilot test from the problems in the literature and the problems they wrote by considering the attainments in the secondary school seventh grade syllabus. The pilot test was examined by 3 experts in mathematics education. The pilot test revised according to expert views was administrated to 20 seventh grade students from eight different schools. As the students could not answer item 2, 5, 7 and 10, they were removed from the data collection tool in line with expert views. The final version of PST, which includes six items, is given in Appendix 1.

The data collection process was realized in two stages. First of all, PST test administrated to 250 students in the eight secondary schools in a course hour. Later on, based students' answers on the PST semi-structured interviews were made with 9 students in different proof schemes. The interviews were recorded upon students' consent. Finally, the voice records were transcribed and analyzed.

In the analysis of the data obtained in the study, the answers students provided were classified according to proof schemes developed by Harel and Sowder [29]. In the classification process, the researchers first analyzed twenty tests together and then continued the analysis independently by sharing the remaining tests. After that, the researchers met at certain intervals to compare the classifications they had made and continued the analysis. However, when any one of the researchers was indecisive with regard to classifying any answer, they checked each other's classifications and discussed over the problematic ones to agree upon the right classification. After the classification process, fit coefficients for analyses ranged between $86 \%$ and $98 \%$. The goodness of fit index between the researchers was calculated using the formula [(Agreement /Agreement + Disagreement) x100)] developed by Miles and Huberman [43]. The codes the researchers used in the classification process are given in Table 1.

Table 1. The Codes used in the classification of proof schemes

\begin{tabular}{|c|c|c|}
\hline $\begin{array}{c}\text { Proof Scheme } \\
\text { (Code) }\end{array}$ & $\begin{array}{c}\text { Proof Scheme } \\
\text { (Code) }\end{array}$ & $\begin{array}{c}\text { Proof Scheme } \\
\text { (Code) }\end{array}$ \\
\hline $\begin{array}{c}\text { External Proof } \\
\text { Schemes (A) }\end{array}$ & $\begin{array}{c}\text { Empirical Proof } \\
\text { Schemes (B) }\end{array}$ & $\begin{array}{c}\text { Analytical Proof } \\
\text { Schemes (C) }\end{array}$ \\
\hline Ritual (AR) & Inductive (BT) & $\begin{array}{c}\text { Transformational } \\
\text { (CD) }\end{array}$ \\
\hline Authoritarian (AO) & Intuitive (BS) & Axiomatic (CA) \\
\hline Symbolic (AS) & & \\
\hline
\end{tabular}

After the answers students provided on the PST were classified, percentage and frequency distributions for each question were developed for each question. Later on, to increase reliability of the classification, semi-structured interviews with a total of nine students, three students from each of the A, B and C schemes, were made. The researchers descriptively supported the classifications based on students' answers and the transcription of interviews. 


\section{Findings}

Table 2. Percentage and frequencies with regard to classifications of students answers

\begin{tabular}{|c|c|c|c|c|c|c|c|}
\hline Questions & AO & AR & AS & BT & BS & CD & CA \\
\hline & $\mathrm{f}(\%)$ & $\mathrm{f}(\%)$ & $\mathrm{f}(\%)$ & $\mathrm{f}(\%)$ & $\mathrm{f}(\%)$ & $\mathrm{f}(\%)$ & $\mathrm{f}(\%)$ \\
\hline 1 & $37(14,8)$ & $66(26,4)$ & $12(4,8)$ & $120(48,4)$ & $14(5,6)$ & $1(0,4)$ & 0 \\
\hline 2 & $10(4)$ & $46(18,4)$ & $6(2,4)$ & $168(67,2)$ & $20(8)$ & 0 & 0 \\
\hline 3 & $66(26,4)$ & $112(44,8)$ & $9(3,6)$ & $49(19,6)$ & $14(5,6)$ & 0 & 0 \\
\hline 4 & 0 & 0 & $211(84,4)$ & 0 & $12(4,8)$ & $27(10,8)$ & 0 \\
\hline 5 & $39(15,6)$ & $21(8,4)$ & $15(6)$ & $31(12,4)$ & $141(56,4)$ & $3(1,2)$ & 0 \\
\hline 6 & $29(11,6)$ & $32(12,8)$ & 0 & $157(62,8)$ & $32(12,8)$ & $7(2,8)$ & 0 \\
\hline
\end{tabular}

When Table 2 is examined, the answers students provided for the first question are in proof schemes at levels A, B and C. The answers for this question are mostly at level B. The students answers at level B is distributed between BT and BS at $48,4 \%$ and $5,6 \%$, respectively. However, $14,8 \%$ of the answers at level A belong to AO, 26,4\% of them belong to AR and $4,8 \%$ belong to AS schemes. As for level C, it was seen that only one students provided proof in CD scheme (0,4\%). The sample answers provided for the first question and student views with regard to each scheme are given below.
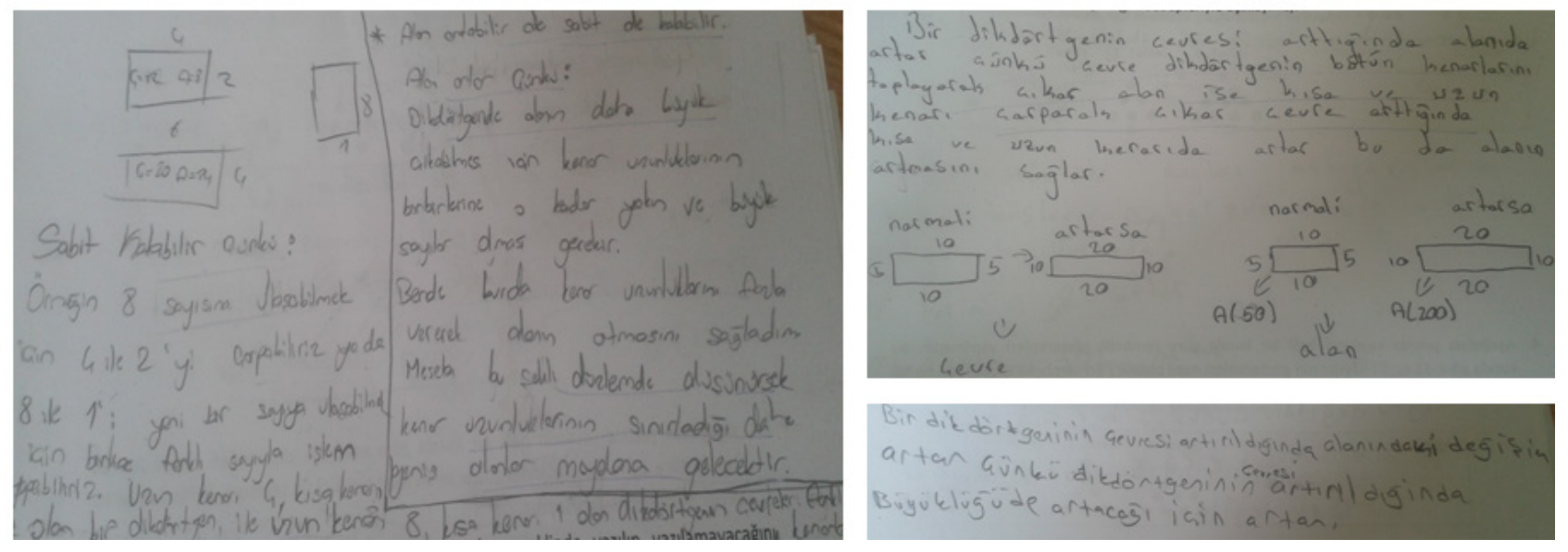

Figure 1. Examples of student answers for the first question

\section{Question 1}

Please explain how will change in the field, when rectangle's perimeter increase. (Explain reasons for rectangle's field will be increase, decrease or stabil)

Interviewer: How did you decide whether the field increased, decreased or remained stable?

S(AO): I found it by drawing it on the paper. Our teacher also told us to do so. I tried even numbers; the long side is 4 and the short one is 2 . And I found that rectangle's perimeter was 12 and field was 8 . I increased its perimeter; I changed the sides as 6 and 4 . I found its perimeter to be 20 and field as 24. When the perimeter of a rectangle increases its field increases as well. I think everything my teacher tells is correct because s/he could not have become a teacher if it were not correct because s/he studied it. I need to make a lot of research to find something my teacher has not told us.

S(AR): Because as the length of the perimeter increases, the upper side and short side increases proportionally and thus the field increases as well. The more we enlarge it, the bigger it becomes. That is, they are proportional to each other. I gave examples here. I think it will increase in general but in some exceptional cases it can decrease or stay stable.

S(AS): I wrote that the fields should increase ... As the shape becomes bigger, the lengths of its sides should increase and thus the field should already increase as well.

S(BT): I changed the numbers on the sides of the same rectangle. In the first case, perimeter was 12 and in the second it was 20; I increased it.

S(BS): If it perimeter increases, normally its field should increase as well because we multiply the short side with the long side when calculating the field. Automatically when these numbers increase, the field increases well.

S(CD): For example, we might think that the field of 5 and 4 is 20 , it perimeter is 18 . But when we try distant numbers, for example 1 and 6 ; its field is 6 , perimeter is 14 . If two numbers are distant from each other, its field is larger. Even if the perimeter of the two numbers are equal, if numbers are distant their perimeter is small as well.

For example, 4 and 5 are very close to each other and when we multiply them, its field is 20 and perimeter is 18 . Its perimeter is smaller than its field. When its perimeter is increased, for example I can make it 2 and 8 , the field becomes 16 and perimeter becomes. Now the opposite case 
emerged. In the first case, the perimeter was 18 and now it is 20 , its perimeter increased. In the first case, field was 20 and now it is 16 , it decreased. That is the perimeter increased but field decreased. That is perimeter increased but the field decreased. I can find that field would not change from the multiplication of common numbers. $5 * 4=2010 * 2=20$. In the first case, perimeter is 18 , in the second case it is 24 . Perimeter increased but the field did not change.

For an example of a case where perimeter and field increase: $6 * 7=42,7 * 8=56$. In the first case perimeter is 26 , in the second case it is 30 . Its perimeter increased, and its field increased as well. When it is said that the perimeter increases, all three cases are possible: it can increase or decrease, or does not change. It varies according to the lengths of these sides. The proximity of the side lengths are also important in increase or decrease in field.

Interviewer: Do side lengths have to increase for increase in perimeter?

S(AO): It is a must because perimeter is found by adding side lengths. Then it is a must for side lengths to increase for the lengths of perimeter to increase.

S(AR): Increase in the perimeter depends on increase in the lengths of sides. According to the answer I provided, it is a must for side lengths to increase for perimeter to increase. In the solution I made, I think I increased side lengths. For example, here $\mathrm{a}=10 \mathrm{~cm}$, there $\mathrm{aa}=20 \mathrm{~cm}$, it enlarged.

S(AS): As I think increase in perimeter is related with the enlargement of the shape, side lengths are to increase absolutely.

S(BT): If perimeter will increase, I think side lengths are to increase as well because if side lengths were 7 and 2, the perimeter would be 18 ; for example, if their lengths were 4 and 1 , it would be smaller.

S(BS): For example, side lengths of rectangle can be 5 and 6. But we can make it larger; as the shape is enlarged, its side lengths increase automatically and when side lengths increase, perimeter increases as well.

Interviewer: Do you think you can convince someone else in the statement in the question with the solution you provided?

S(AO): Yes. My friend can be convinced with the solution I made because I tell something correct.

S(AR): To convince someone, I need to solve more questions and give more example. Perhaps I can make more explanation by increasing my knowledge.

S(AS): I think I can ... because I do not think the things I tell have nothing that will confuse others.

S(BT): I would draw lines just as I did when I found my answer, I already think it can be better understood by giving examples directly on it.

S(CD): Yes because the perimeter of a rectangle is the multiplication of the short side with the long side. That is I can find it by trial as long as I know the formula for field. I convince them with the examples I give, everything is clear because I reach a rule from the examples I give.
Interviewer: What other ways can you try for the solution of this problem?

S(AO): I cannot do anything other than this because our teacher explained us that much. Perhaps there is another way for solution.

S(AR): When I think about a rectangle, I probably would not be able to explain it in another way. I can only do this in this way.

S(BT): If there were a rectangle on a isometric paper, we could solve it with lines there. We would be able to solve it with units.

S(BS): I would design in mind before drawing. It would not be possible without drawing; I mean I cannot know how to tell.

S(CD): Yes because it is something provable with the examples I give.

Interviewer: Do you think the solution you have made is correct?

S(AO): Yes. I think it has no fault. Whenever perimeter of a rectangle increases, its field increases as well.

S(AR): Yes because lengths ( the students draws a line meanwhile) are proportional, if we say 16 , the short side gets longer as this side gets longer. Therefore, I think it is correct.

S(BT): No because this is not the absolute answer, if we assign different numbers, different results would appear. Perhaps it decreases. My answer is not incorrect, I said it increases but it should also decrease. So it is deficient.

S(BS): I think it is correct. When perimeter increase, why does not it increase, it increases absolutely.

S(CD): I think it is correct, when I make generalization. I see it from the examples I give.

In the first question, the students were asked a problem case with regard to change in the field of a rectangle when its perimeter is increased. In this problem, students are to be able to understand three cases: increase, decrease and no change. However, almost all of the students could not realize. Only one student in CD proof scheme could clearly explain that the field can increase, decrease or not change. All of the rest thought that the field of a rectangle should increase when the perimeter of a rectangle increased and made explanations in line with this. This is supported by the interviews with students from different proof schemes.

When the proofs students made with regard to the second question are examined, proof scheme at B level (BT 67,2\%, BS $8 \%$ ) is used frequently used. Therefore, the students mostly fictionalized their proof on examples as in the first question. However, from the answers of the students it is seen that those in the proof scheme A are distributed as follows: AO 4\%, AR 18,4\% and AS 2,4\%. Besides, it was seen that there is not any answer in proof scheme $\mathrm{C}$ in this question. Examples of the answers provided for the second question and student opinions with regard to each scheme are presented below. 

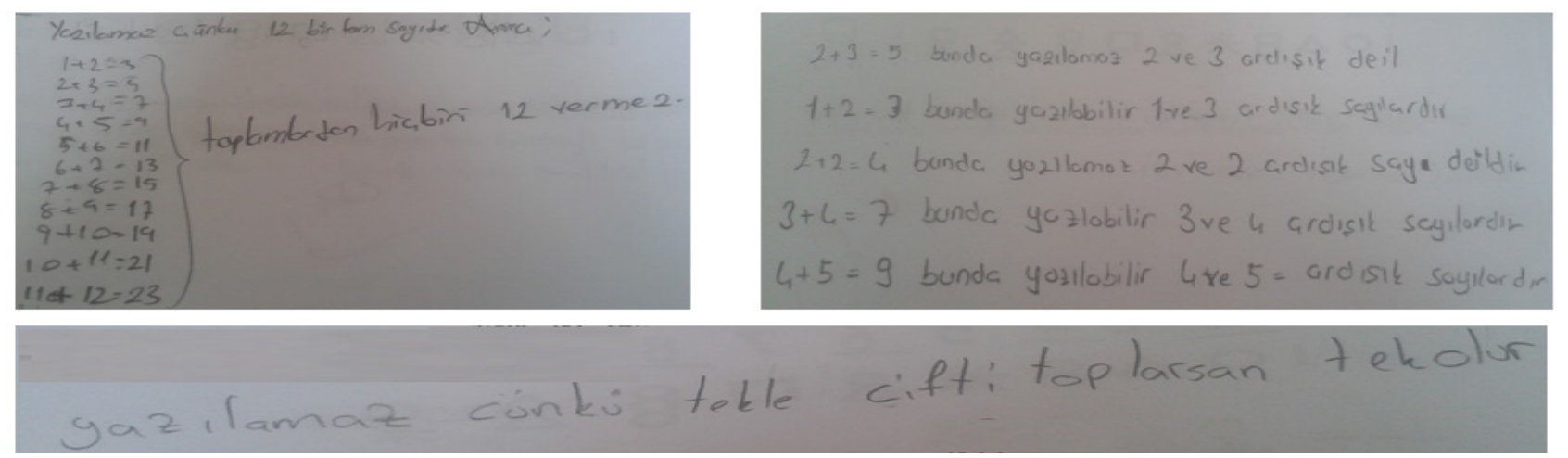

Figure 2. Example student answers with regard to the second question

\section{Question 2}

Explain whether each whole number can be sum of two consecutive numbers or not.

Interviewer: Why did you need to make trials with numbers in your solution?

S(AO): Because our teacher tries to explain such types of questions with examples... I want to make it like her too.

S(AS): I thought that if the addition of two odd numbers is even, addition of two consecutive numbers is so. I intuitively decided that it is the case.

S(AR): Because I know whether the addition of numbers can be counted on the shape or not. I decided according to this.

S(BT): I gave examples as I thought that perhaps I have not been able to tell exactly with definition. I wanted justify and prove with examples.

S(BS): Because, as it said consecutive numbers, I thought that we could explain it by giving examples with numbers. Therefore, I did such a thing.

Interviewer: Can you convince someone else in the statement of the question with the examples you have given?

S(AO): Yes. The examples I gave are enough.

S(AS): Yes... If the example I gave is correct, it can be believable for others as well.

S(AR): I mean normally someone who believes that it is correct, believes that the other is correct as well. How can I prove it? Probably by giving examples, I prove by giving examples. I explain it to my friends with examples.

S(BT): I think I convince others because explanation is clear it is already obvious. Giving only one example is not enough to convince someone because for example s/he might say $2+3$ for one (question) but cannot think it is the case for other consecutive number. I think more than one examples would be more sufficient.

S(BS): It can be told without giving examples but would it be difficult to prove? I would have difficulty in convincing.

Interviewer: What other ways can you try for the solution of this problem?

S(AO): I would not be able to make it without giving examples, how would it be possible without numbers?

S(AS): I cannot think of another way because I believe what I do is correct.

S(AR): No, I would not think of (another way) because I generally have only one answer. Single and clear.
S(BT): I would not use another way, it reads two consecutive whole numbers; what can I do. I gave example and made explanations. I might be asked to find other things to prove it to convince others. They may want me to develop my explanation; I think they will understand from the examples.

S(BS): It is not possible to give numbers and make additions because I think consecutive numbers cannot be shown in any other way as they follow each other. We need to give examples.

Interviewer: Do you think your solution is correct?

S(AO): We always solve such questions in this way, so I think it is correct.

S(AR): Yes. Because I make it feeling sure. I mean I do not do anything without being sure I do it feeling sure. If I were not sure I would not do such a thing.

S(AS): The thing that makes me feel sure is my idea at that time. I must have done it however I thought at that time.

S(BT): I think they are correct, from my examples because I added too many two consecutive whole numbers, they do not add up to even numbers.

S(BS): Yes. I have given examples, it is seen that it is correct.

The fact that the answers provided by the students with regard to the second question are generally in B proof scheme indicates that students try to explain the proofs they made via examples. The students in A proof scheme also tried to explain their answers with examples. Therefore, in this question students could not develop different thinking processes. They only made guesses or made example based explanations.

When the proofs made for the third question are examined, it is seen that students' answers are in level A and level B proof schemes. However, for this question proofs at level A predominate. Students' A level proofs are distributed as follows: AO 26,4\%, AR 44,8\% and AS 3,6\%. The fact that the students are in $\mathrm{AR}$ and $\mathrm{AO}$ schemes for this question stems from the fact that they use their own knowledge and expressions of their teachers. However, it is seen that $19,6 \%$ of the proofs at level B are in BT and 5,6\% of them are in BS schemes. Besides, as in the previous question, there is not any answer in $\mathrm{C}$ proof scheme. The examples of the answers provided for the third question and student views with regard to each scheme are given below. 

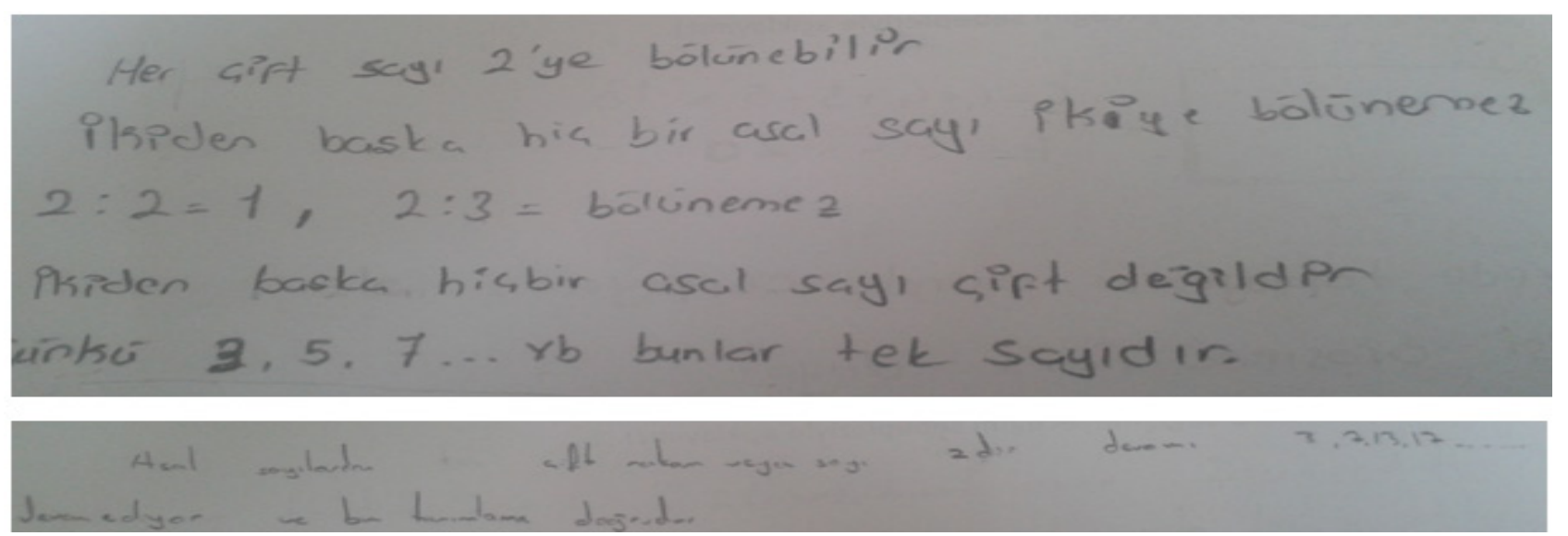

Figure 3. Sample student answers for the third question

\section{Question 3}

Is "All even numbers divisible by 2 , no prime number is divisible by 2 without 2 so 2 is the only even prime number" right? Please, explain with reasons.

Interviewer: How did you decide that the statement in the question is true with the explanation you have made?

S(AO): Because our teacher told us the prime numbers and made this definition.

S(AS): I was not able to answer to this question because I was missing when the topic of prime numbers was taught. The things we understand from books by reading is never the same as what the teacher teaches us. For example, my friends tell me as much as they have understood. But the teacher tells me in more details and in a better way as $\mathrm{s} / \mathrm{he}$ knows the whole topic. But there are parts my friends did not understand and I did not understand the topic very well as they reflect it (the deficiency in their understanding) when they tell me.

S(AR): Generally prime numbers are those which can be divided by themselves and by 1 . As 2 follows 1 , it can only be divided by itself and by 1 . Therefore, I decided that 2 is the only even prime number. That is I know the definition of prime numbers; the number 2 is the only even prime number.

S(BT): I wrote down prime numbers. Prime numbers are defined as numbers which cannot be divided by any number other than itself and 1. No prime number other than 2 can be divided by 2 . For example, 1, 5, 7, 11 cannot be divided; they cannot be divided by 2 . But not every number which cannot be divided by 2 is prime number. 15, for example, ca it can be divided by 3 and by 5 . It is not a prime number. Here I gave examples following from prime numbers.

S(BS): The definition given with regard to prime numbers in the question is correct for me ... I cannot remember any even prime number.

Interviewer: Can you convince anyone in the statement given in the question with the examples you gave?

S(AO): I think it will be convincing because I used exemplification here; besides we learnt the same in the course. Those who know these also know them. I believe that one can realize it if $\mathrm{s} / \mathrm{he}$ thinks a little.

S(AS): Because when I tell the concept of prime number, everything becomes clear. I will tell his/her if $\mathrm{s} /$ he does not know the concept of prime number. The number is prime number if it is divided by itself and by 1 ; if it has other divisors like $2,5,7$, it is not a prime number. If it does not work, I give examples like $-5,-3,-2,3, \ldots$.

S(AR): If there is a simpler and less complex definition, it can help them understand it better but I do not know. That is I thought when I was writing this, finally I was convinced but I do not know it is a little bit confusing.

S(BT): I would convince, because no number other than 2 can be divided by 2 . I have shown that prime numbers cannot be divided by 2 by giving examples of prime numbers.

S(BS): Besides the definition, examples can also be given to convince because $\mathrm{s} / \mathrm{he}$ can understand it following from an example but she might not be convinced if $\mathrm{s} / \mathrm{he}$ knows what a prime number by its definition. There I wrote a definition because I thought that it would be sufficient.

Interviewer: What other ways can you try for the solution of this question?

S(AO): Numbers can be given as examples. Even number 14, for example, can be divided by 7,2 and by itself. This is already given in the definition of prime number; it can be divided by itself. It can be divided by two other numbers other than itself. That is it is not a prime number I can give such examples other than the definition.

S(AR): There is not a different way I think. I mean if I made it again, I would answer with the definition of prime numbers.

S(BT): I would try to give example again. No other way to explain this definition comes to my mind.

S(BS): It can be based on the definition or numbers can be given (as examples). For example, I would give examples of odd numbers; for example 15 can be divided by 3 and 5 . I would give an even number; 8 can be divided by $1,8,2$ and 4 . It can be divided by many numbers, that is, in this case 8 cannot be a prime number. Explanations can be made by giving such examples.

Interviewer: Do you think the solution you found is correct? 
S(AO): I believe it is correct because they taught it in the class if it were incorrect they would not have thought it in the class.

S(AS): We can conclude that it is correct following from the definition of prime numbers.

S(AR): Yes, I am sure. I can show its accuracy both by the definition and by the examples.

S(BT): Yes, correct. My definition matches with the definition of prime number. The examples I gave support the definition.

S(BS): Correct but it can be deficient. I would show that odd numbers cannot be divided by 2 but they are not prime number because they have other divisors.

In the third question, the students were asked to show the accuracy of the explanations they made with regard to prime numbers. When the student answers and transcription of interviews related to this question are examined, it is seen that proofs at level A are predominant. This case caused increase in proofs in AR scheme which requires students to question their knowledge to justify the definition given in root of the question. Similarly, the proofs in AO scheme, which require teachers or textbooks to be used as evidence, were used frequently. Besides, proofs in BT scheme, which

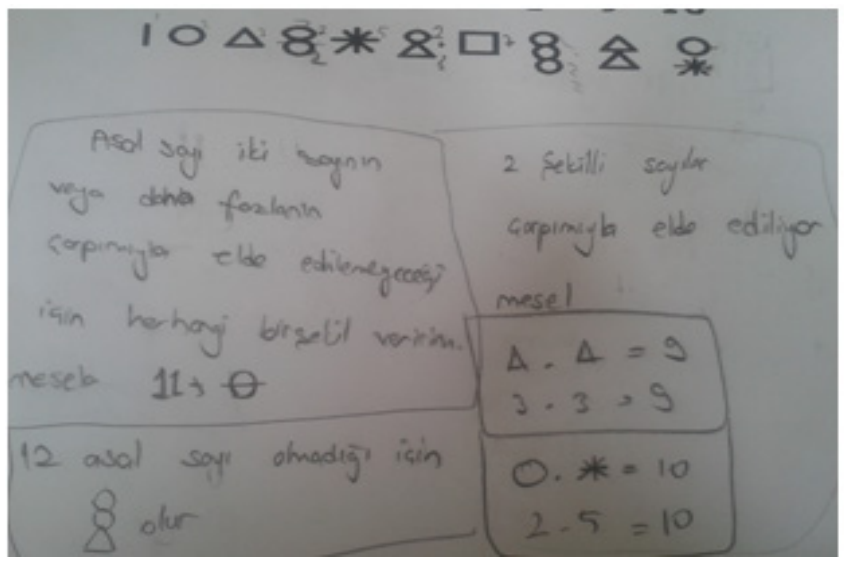

are made with trial-error, were also used by the students. However, it was determined that there is not any answer in scheme $\mathrm{C}$, which requires the transformation of problem case into different formats and formation of different deductions.

When the answers students provided for the fourth question are examined, it is seen that there are proofs in proof schemes at A, B and C levels. In this question, different from other three questions, it was seen that at level A there were only proofs at AS scheme and they were used at a very high rate as $84,4 \%$. The high percentage of answers in AS scheme can be attributed to misinterpretation of the pattern given and therefore to the use of wrong shapes for the numbers 11 and 12. However, it is seen that $4,8 \%$ of the proofs at level B belong to BS scheme. Again different from other questions, in this questions students tend to give intuitive answers instead of trial-error. Besides, the percentage of the candidates in $\mathrm{CD}$ proof scheme at level C $10,8 \%$. It was determined that the students in $\mathrm{CD}$ proof scheme understood the pattern completely and reached the conclusion that different shapes must be used for each prime number. Samples from the answers provided for the fourth question and student views for each scheme are presented below.

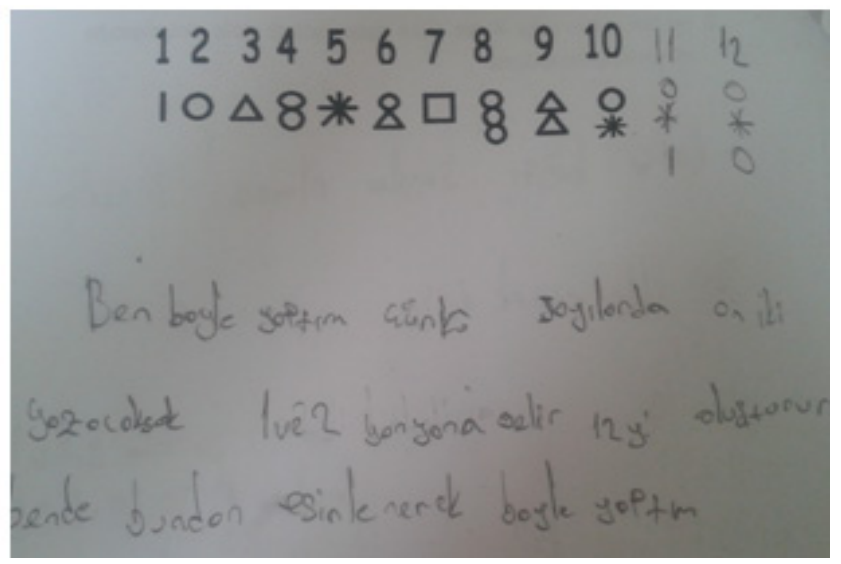

Figure 4. Sample student answers for the fourth question 


\section{Question 4}

Symbolic representation of numbers is given by rule in the following figure. How can representations of 11 and 12, according to this rule? What kind of things did you discover from this symbolic array?

Interviewer: What did you think about the numbers and symbols in this question?

S(AS): Between the numbers and symbols are for example, there is a triangle for 3 as it has three sides, there should five lines for give and the symbol for 8 seems like eight.

S(AS): There is a pattern here, in a pattern things consecutively follow each other. For example, we were asked 11 and 12. This means that the rule of the pattern finished at 10; I thought that the rest will be found by turning back to the beginning. Therefore, I draw the symbols of 1 and 2 for 11 and 12, respectively.

S(BS): For the number 12 and for other even numbers, circle is used. Half of 12 is 6 , so I added another circle for 6 . I thought circle was used for every second number and circle is removed in numbers which are the half of it. I added another circle to the symbol of 6 , as half of 12 is 6 .

S(CD): When I look at these shapes, for example there are two same shapes in 4 , the same shape as in 2 . This can be $2 * 2$ or $2^{2}$ or $2+2$. But when I looked at the other numbers for $6, \mathrm{I}$ saw that $3+2=5$ but $3 * 2=6$. It cannot be its square as well. $3^{2}$ equals to 9 . I saw that there were multiplications of shapes there. To show 11 and 12, I thought as follows: as 1, 2, 3, 5, 7 are prime numbers, you have given them shapes because they have no other divisors, if there were, they would have a multiplier as well. AS a prime number cannot be obtained with the multiplication of two or more than two numbers and as 11 does not have another divisor, I shaped it as thought. As 12 is not a prime number, it would be the multiplication of different numbers. The order of the shapes is not important for example as the multiplication of $3 * 2 * 2$ and $3 * 4$ are the same, nothing changes.

Interviewer: What other relations can be seen for the solution of this question?

S(AS): There can be other solutions. There are certainly other solutions because this is a question which requires a lot of interpretation. For example, if I think of a different solution, I could draw two sticks for 11 and two sticks and a circle for 12. I would use the symbols for one and two.

S(BS): Actually another way can be used. For example, here we solved by looking at the shapes but a pattern can be found between them.
S(CD): Here a mathematical operation like multiplication might have been applied here. Someone who discovers this operation can solve it with another method.

Interviewer: Do you think the solution you have made is correct?

S(AS): I do not think that it is directly correct because I also found different results; I cannot directly say it is correct. I cannot be sure of the solution when I cannot find an absolute answer; that is when I find different ways.

S(BS): It is correct. I have a look at the other numbers, as they always repeat them, as I have continued after I have found the pattern, I am sure.

S(CD): I am sure because numbers are multiplied. 11 does not have a multiplier, it is a prime number, so it must be shown with a different shape. I wrote explanations to convince others, with examples. I wrote the numbers obtained with the multiplication of two numbers, for example multiplication of triangle with triangle is 9. I would explain in this way by giving examples.

The answers of the students to the fourth question and the interviews indicate that the root of the question is influential on students' proof schemes because in this question, students are expected to understand the rules of pattern and apply the rule of the pattern for different numbers. The proofs students made with regard to this question are different from their proofs for other questions. It was determined that most of the students were in AS proof scheme as they did not understand or misunderstood the pattern rule.

Besides, intuitive answers and guesses caused proofs at level B to be included in BS scheme. The answers of the students who discovered the rule in the pattern and transformed them into shapes that could be used for different numbers were in CD scheme.

When the proofs students made for the fifth question are examined, it was seen that there are answers in proof schemes at A, B and $\mathrm{C}$ level. For this question, the proofs at level $\mathrm{B}$ are in majority. $12,4 \%$ of the students' proofs at level $\mathrm{B}$ are in BT and 56,4\% are in BS. The students were mostly in BS scheme because they could not form the rule of the pattern clearly and tried to make guesses. Besides, it is seen that $15,6 \%$ of the proofs at level A were in AO, $8,4 \%$ were in AR and $6 \%$ were in AS scheme. As for level C, only $1,2 \%$ of proofs were in CD scheme. The examples of the answers for the fifth question and student views with regard to each scheme are given below. 

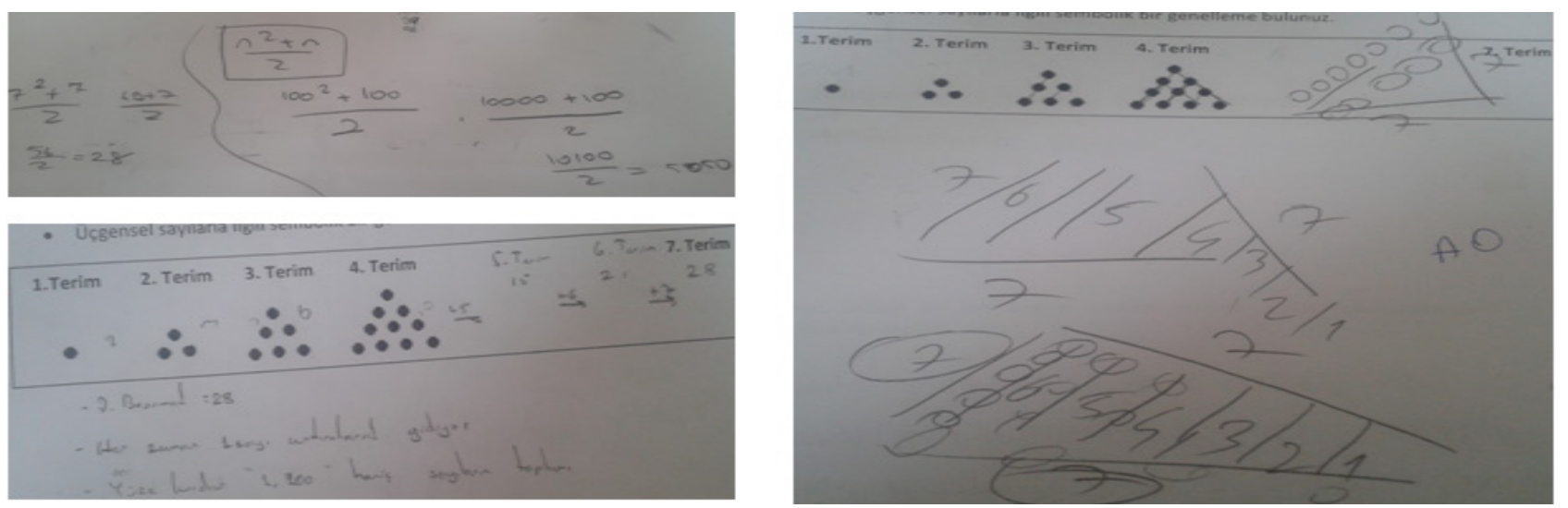

Figure 5. Examples of students' answers are given below

\section{Question 5}

Symbolic representation of numbers is given by rule in the following figure. How can representations of 11 and 12, according to this rule? What kind of things did you discover from this symbolic array?

Interviewer: What can you say with regard to the relation between the terms?

S(AO): There is a rule for it, the pattern has a rule. I need to find that rule.

S(AR): In the first term, one bead is used underneath, in the second term there are 2 beads and the beads are put one on the top of another in the descending order, that is like in a pyramid.

S(BT): Here there is a bead in the first term, in the second term it was increased by two and there are three beads. I found the terms by writing terms and increasing them.

S(BS): I looked at its pattern. The increase from the first term to the second term was 2 , the increase from the second term to the third term was 3 , that is, I saw that it followed consecutively.

S(CD): I first did such a thing: I wrote numbers (of beads) under the terms, 1, 2, 3 and so on. In such cases, we are supposed to write " $n$ " to indicate the amount of increase but here there is not a certain number for the increase. It increases by 2, 3 and 4. Therefore, we cannot say something like $3 n, 4 n$. I said n, and then I looked at the number that coranswers, later I was going to use things like $n^{2}, n^{3}$; first of all I tried $n^{2}$. When I tried $n^{2}$, the square of 2 is 4 and when added it with $\mathrm{n}$ it yielded 6 , but the term was 3 , so I divided it by 2 and found 3 . I found the second term in this way. Later on, I tried to find other terms and saw that the rule I found was correct.

Interviewer: How do you think the seventh term can be found?

S(AO): I was not able to find the seventh term as I could not find the rule of the pattern.

S(AR): I put seven beads at the bottom and them 6 beads above it and 5 for the next. It goes on like this. That is you are supposed to place as many beads at the bottom as the number of the term and it goes on in a descending order to form a pyramid.

S(BT): I went on by increasing the number between the terms; I increased the number by 4 from the third term to the fourth, 5 from the fourth to the fifth, 6 from the fifth to the sixth term, 7 from the sixth term to the seventh and I found that the seventh term was 28 .

S(BS): I wrote down the terms and increased them.

S(CD): I placed in the formula I found: $\left(7^{2}+7\right) / 2=28$

Interviewer: How do you think you can find the hundredth term?

S(AO): I tried to write the hundredth term, I thought that it would take too much time so I gave it up. I mean, this shape is to be drawn to find the 100th term. 100 beads at the bottom line and next 99, the pyramid will be completed in this way. Our teacher should teach us; otherwise we cannot solve such a question when we meet it.

S(AR): I was not able to find the 100th terms as I was not able to find the pattern rule, if I had found, I would have done it very easily.

S(BT): We can find it by increasing it like this but this is the long way, there is a short formula for it We can do it with or without the formula but is difficult to find the 100th term without the formula. As the seventh term is a small number, it is found easily but the formula is to be used larger terms.

S(BS): It needs to be increased by 100 items for the 100th term; it would be very difficult to do it by drawing. We need to find the rule to solve it. But if I do not know the rule, I will not be able to do it ; I cannot understand by looking at it. I need to learn this rule. Perhaps I would be to find it on my own but I would have a lot of difficulty, I would not even be able to find it. I need to know the rule and place the numbers in the rule.

S(CD): I did it again by using the formula. If I did not find the Formula, I would have to try again and again. It increases one by one, it can be found by adding again and again. I need to go on by trying it one by one. It would take long, when I found the rule, it was revealed.

Interviewer: Do you think the solution you have made is correct?

S(AO): Now I do not think that I did it correctly, I would be able to do if found the general term. 
S(AR): As I have expressed with the shape, I think it is a correct solution. I would draw shapes to convince others, I would ask my interlocutor to count them. S/he would be convinced when we compare our answers.

S(BT): The solution I provide is correct; we draw as many balls at the bottom as the number of the term we want to find.

S(BS): Yes, we were able to find it because of the shapes. For example, the sides have been increased so the number of the balls in this shape has increased as well. If we want to find, we have to try by drawing. It cannot be done without drawing.

S(CD): Yes. There is a rule for it. By applying the rule, you find the correct answer no matter which term it is.

It was seen that as for the fifth question only the proofs of the students in CD proof scheme could found the 100th term. As the students in this scheme could determine the rule of the pattern, they were successful in all cases asked. However, the students who gave answer based on trial error (BT) and
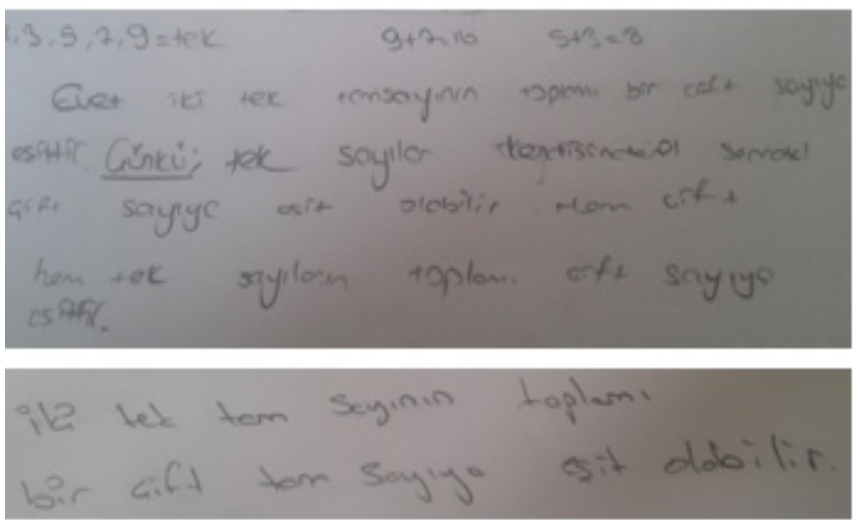

intuition (BS) could answer the question related to the 7th term. It was seen that the answers of these students with regard to the 100th term were wrong or they did not answer it at all. From the proofs at level A, it was seen that the pattern was not understood by the students and invalid evidences were presented.

It is seen that the answers the students provided for the sixth question were in proof schemes at levels A, B and C. In this question, the number of the proofs it level $\mathrm{B}$ are in majority. The proofs of the students at level B are distributed as follows: $62,8 \%$ BT and $12,8 \%$ BS. The students were mostly in BT scheme because they made use of examples and used trial-error method. However, it is seen that their proofs at level A were distributed as follows 11,6\% in AO scheme and $12,8 \%$ in AR scheme. As for level C, it was seen that only $2,8 \%$ of the answers were in $\mathrm{CD}$ scheme. The examples of the answers provided for the sixth question and student views with regard to reach scheme are given below.

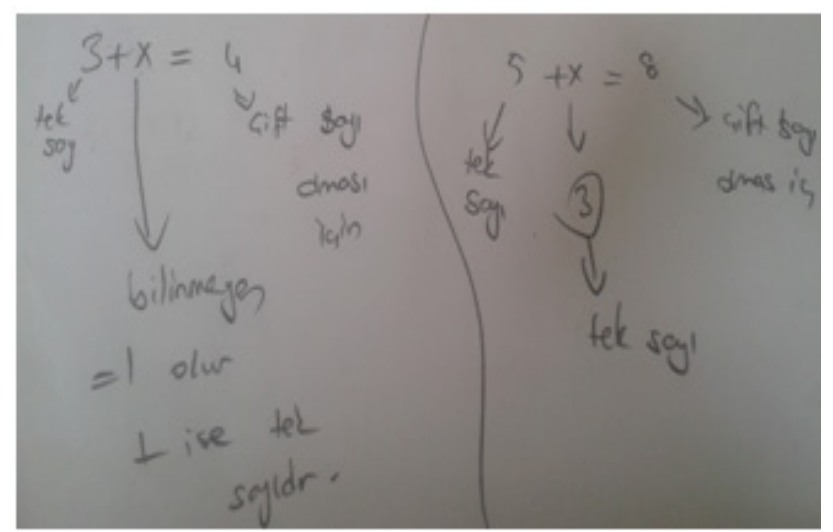

Figure 6. Examples of students answers for the sixth question 


\section{Question 6}

Show that two odd numbers always equal an even number.

Interviewer: Do you think the example you provided is sufficient to explain this statement?

S(AR): I thought that others had already found, why should it be found again? Then I tried. $1+1=2$ and $3+5=8$. By trying I always see that addition of two odd numbers is even.

S(BT): More example helps clearer explanation. But here I gave two examples. We can increase the number of the examples. When the number of examples increase, it will be easier to convince others.

S(BS): We say two odd numbers that is we say 2 so the addition of two odd numbers is even. Different examples can be given but I saw the example I wrote as sufficient.

S(CD): First of all I chose an odd number. I wrote "odd number $+x=$ even number" $(3+x=4)$. According to the equation this should be 1 . As it is 1 according to the equation, addition of two single whole numbers is even. But it might be coincidence so I made another trial. I said $5+x=8, x=3.5$ and 3 are odd numbers, so it is odd number in both cases. So the answer is even number. I did not whether the unknown number will be odd or even. For example, the addition of two odd numbers is even, it is a definition. I wrote an even number opposite it and I wrote $\mathrm{x}$ for its addition with an odd number. As I did not know the value of this rule without a number, I wrote an equation and tried. It can be correct here but it could be wrong with another number. So, I found the value by writing an equation.

Interviewer: Can you convince someone in the statement of the question with the explanation you have made?

S(AR): If a friend of mine asked me this question, I would give this answer. I would tell it is the rule but if I was asked this in an exam I would find by trial.

S(BT): I can convince. For example, I would put an apple in one, and then when another apple comes next to it, it would be even. I would say, therefore, addition of an odd number to an odd number is even according to mathematics. That is, I am modeling it.

S(BS): I would want him/her to tell me an odd number. I would add them and $\mathrm{s} /$ he would also see that the result is even.

S(CD): Yes, because I have a rule in my hand. I have examples. I have a rule following from the examples. If they ask me, I can answer with examples.

Interviewer: What other ways can you try for the solution of this question?

S(AR): By trying, I see that addition of two odd numbers is even.

S(BT): One can use logic but examples come to my mind always. I can explain better by giving examples.

S(BS): It might have been tried but it does not come to my mind. Only explanation or only exemplification might be used. I can give other examples too.

S(CD): There is no need for anything else; this is enough to convince anyone.

Interviewer: Do you think the solution you have provided is correct?

$\mathbf{S}(\mathbf{A R})$ : Definition is correct; when I try with the numbers, it gives correct answer.

S(BT): I think it is correct, the way I found via trial is correct. There is no opposite example.

S(BS): I gave correct examples but my explanation is inadequate. I think there is only deficiency.

S(CD): Yes. If I get the same result with everything I try, it means that it is correct. I prove everything with trial.

When the answers and interviews with the students are examined, it is seen that the proofs students provided for the sixth question were made with the help of examples and as a result of trail-error process. Generally with one or a few examples they gave, the students decided that addition of two odd numbers would be even and they were convinced with the proof they made. However, the students in CD category transformed odd numbers into $2 n+1$ form and they generalized their proof in this way. It was seen that the students who made proofs at level A were not sure about their proofs.

\section{Conclusions, Discussion and Recommendations}

The results of the study, which aims to determine current proof skills of secondary school seventh grade students and to which proof scheme, according to Harel and Sowder [29] proof schemes, the proofs they made belong, are discussed in this section of the study. According to the findings of the study, it can be said that proof making skills is not at adequate level because the proofs students made were generally in A and B proof schemes. Dede and Karakuş [44] stated that as analytical proof schemes form the basis foundation for mathematical reasoning, students' use of external and empirical proof schemes in mathematics is not desirable and analytical proof schemes are superior to them. Therefore, students' ability to make the proof in this scheme is closely related with their proof skills. However, while the transformational proof scheme coded as CD, which is one of the analytical proof schemes, is used rarely for the problems on the PST, there was not any student who could use axiomatic proof scheme coded as CA.

According to the students' answers on the PST and interviews, it was seen that $\mathrm{A}, \mathrm{B}$ and $\mathrm{C}$ proof schemes were used for 1st, 4th, 5th and 6th problems; however, only A and $\mathrm{B}$ proof schemes were used for 2 nd and 3rd problems. Besides, it was understood form the interviews with the students that student using different proof schemes were sure that their proofs were correct. This finding of the study is compatible with Harel and Sowder [29] because Harel and Sowder [29] stated that same students do not always have only one proof scheme and in some cases they could use different proof schemes at the same time. Besides, in spite of the fact that the proof students make seem to be the same, the reasoning processes they use can be different [45]. Therefore, 
although there were students who used the same proof scheme for different problems, it was seen that generally students used different proof schemes for different problems.

The proof schemes of the students generally changed because of the change in the root of the question. It was seen that students could make different deduction for the 4th and 5 th problems, which required them to search pattern. Especially, for the 4th problem, the students who could understand the mathematical correspondence of the relation between shapes and numbers were in CD proof scheme and those who could not understand it were in AS proof scheme. Similarly, the students who formed mathematical expression of the pattern for the 5th problem were in the CD proof scheme, other students made intuitive or guess-based proofs. On the other hand, when we formed a question root including the addition of two numbers (2nd and 6th questions), the students' tendency to make proof via trail-error increased. In both questions, the students based their proofs in BT proof scheme on the addition of the numbers in the root of the question, which were chosen appropriately for the problem. Besides, as for the 3 rd problem in which proof scheme A is mostly preferred, the students tried to find a reference point to prove the accuracy of the proposition in the root of the question. The references students determined were trying to remember previous learning, remembering what teacher told or what is written in the text books. In the 1st problem in which proof schemes A and B were used frequently, students tried to make their proofs by giving examples considering rectangles of different sizes or by using a reference which can show the relation between perimeter and field.

Another result of the study is that students from different proof schemes believe that they can convince people to the accuracy of their proofs. The interviews revealed that the students using different proof schemes thought that their proofs were correct and that they could prove the accuracy of their proofs to their friends. However, it was seen that they could not produce any argument when the students were asked to make different solutions other than the proofs they made.

As a result of the study, it was seen that the students were generally in A and B proof scheme. Besides, it was determined that $\mathrm{CD}$ proof scheme was used rarely and $\mathrm{CA}$ proof scheme, which is also a member of $\mathrm{C}$ proof scheme, was never used. The fact that axiomatic proof scheme was not used by seventh grades can be attributed to their ages because it was determined that reaching higher levels in proof schemes was related to class level and there was a upwards tendency towards analytical proof schemes as grades increased [46]. Similarly, in their studies Knuth, Chopin and Bieda [47] concluded that there was a positive increase in students' proof making and justification levels as their grades increased, pupils at early ages might try to make proofs, at simple levels tough and that they could improve these skills in time.

In the study, it was seen that secondary school seventh grade students had tendency to make proof but their skill was inadequate. It was also seen that the student made their justifications via trail-error based on examples. The students who gave answers in $\mathrm{C}$ proof scheme used some algebraic expressions. Similarly, the results of a study by Cooper et al., [48] indicated that students primarily use visual and verbal methods, and finally use algebraic expression when making proofs. In the interviews, it was seen that the students in B and $\mathrm{C}$ proof schemes used mathematical language more effectively when explaining their ideas. In many studies in the literature, the importance of using mathematical language when making proof is emphasized and that students have difficulty in making proof as they do not have an adequate command of concepts and definitions related to proof making [49], [50], [51].

Besides, in our country, it is seen that reasoning, skills like critical thinking, problem solving and making deduction are emphasized instead of proof making [32]. Tall [1] reported that early age children had difficulties in proof making and formal proofs were only appropriate for some students. Therefore, it can be said that seventh graders mostly make proofs through trial-error method or intuitively rather than formal proofs. In this context, there is a close relation between education programs and proof making process and proof schemes [44].

The results of this study are limited with the proofs provided for the 6 problems on PST and the interviews. Therefore, proof schemes of secondary school students can be examined with tests developed according to different proof making methods. Besides, it was seen that the students mostly provided answers in A and B proof schemes. For students to reach $\mathrm{C}$ proof schemes, which are desirable, empirical studies, can be carried out by designing in-class activities. Besides, change in students' proof schemes with in-class activities can be observed to help them develop different solutions for problems. In a study by Bieda [40], the importance of encouraging students, preparing course content that would facilitate problem solving and giving enough time were emphasized. Burns [52], who carried out studies on encouraging student for mathematical thinking, emphasized that pupils are to be provided guidance for making guesses, generalization, reaching judgment, trying alternative ways and develop ideas. In a study by Stylianides [38], the role of the teacher in the class is emphasized for students to develop their own frame of mind and comfortably share it with others and defines the role of the students as a guide who encourages students to ask questions. The importance of directing students' questions that will encourage them to explain why and how their justifications are correct or incorrect is emphasized. Similarly, it is emphasized that teachers should choose appropriate course content and prepare effective activities.

\section{Appendix 1. Proof Schemes Test}

Dear students, this form was prepared on the purpose of determine your proof skills. Your answers to the questions 
on the form will be used only for scientific study and they steer the studies that will be done in the future. It is important to answer considering and attentively.

Thank you for your contribution.

1. Please explain how will change in the field, when rectangle's perimeter increase. (Explain reasons for rectangle's field will be increase, decrease or stabil)

2. Explain whether each whole number can be sum of two consecutive numbers or not.

3. Show that two odd numbers always equal an even number.

4. Is "All even numbers divisible by 2, no prime number is divisible by 2 without 2 so 2 is the only even prime number" right? Please, explain with reasons.

5. Symbolic representation of numbers is given by rule in the following figure. How can representations of 11 and 12 , according to this rule? What kind of things did you discover from this symbolic array?

\section{$\begin{array}{llllllllll}1 & 2 & 3 & 4 & 5 & 6 & 7 & 8 & 9 & 10\end{array}$ $10 \Delta 8 * 8$ 요웅}

6. The first four terms of triangular numbers is given in the following figure. The value of first triangular number is 1 , the value of the second triangular numbers 3 ... For a given triangular numbers;

\begin{tabular}{|lllll}
\hline 1.Term 2. Term & 3. Term & 7. Term \\
\hline
\end{tabular}

- Find 7. Term

- Find 100. Term

- Find a symbolic generalization about triangular numbers.

\section{REFERENCES}

[1] Tall, D. (1998). The cognitive development of proof: Is mathematical proof for all or for some? Conference of the University of Chicago School Mathematics Project, USA.

[2] Hanna, G. (1991). Mathematical proof. In D. Tall (Ed.), Advanced mathematical thinking (pp. 54-61). The Netherlands: Kluwer.

[3] Kitcher, P. (1984). The Nature of Mathematical Knowledge. New York: Oxford University Press.

[4] Polya, G. (1981). Mathematical discovery: On understanding, learning and teaching problem solving. New York: Wiley.

[5] Harel, G., \& Sowder, L. (2007). Toward comprehensive perspectives on the learning and teaching of proof. In F. K. Lester (Ed.), Second handbook of research on mathematics teaching and learning (pp. 805-842). Charlotte, NC:
Information Age.

[6] Lee, J. K. (2002). Philosophical perspectives on proof in mathematics education. Philosophy of Mathematics Education, 16.

[7] Ross, K. A. (1998). Doing and proving: The place of algorithms and proofs in school mathematics. American Mathematical Monthly, 252-255.

[8] Aylar, E. (2014). Examination of 7th grade students' ability on Proving and their perception of proving, Unpublished Doctoral Dissertation. University Of Hacettepe, Ankara.

[9] Gossett, E. (2003). Discrete Mathematics with Proof. Pearson Education, Inc, USA.

[10] Irmak, H. (2008). Abstract Mathematics. Pegem Akademi Publishing, Ankara.

[11] Rossi, R. J. (2006). Theorems, Corollaries, Lemmas and Methods of Proof. Wiley-Interscience, USA.

[12] Aylar, E., \& Şahiner, Y. (2014). A study on teaching proof to 7th grade students. Procedia - Social and Behavioral Sciences, 116, 3427-3431.

[13] Hanna, G. (2000). Proof, explanation and exploration: An overview. Educational Studies in Mathematics, 44, 5-23.

[14] Knuth, E. J. (2002). Teachers' conceptions of proof in the context of secondary school mathematics. Journal of Mathematics Teachers Education, 5, 61 - 88.

[15] Laborde, C. (2000). Dynamic geometry environments as a source of rich learning contexts for the complex activity of proving. Educational Studies in Mathematics, 44, 151-161.

[16] National Council of Teacher of Mathematics (2000). Principles and standard for school mathematics. Reston, VA: National Council of Teacher of Mathematics.

[17] Ball, D.L., Hoyles, C., Jahnke, H.N., \& Movshovitz-Hadar, N. (2002). The teaching of proof, Proceedings of the International Congress of Mathematicians (Ed. L. I. Tatsien), Higher Education Press, Beijing, 3, 907-920.

[18] Healy, L., \& Hoyles, C. (2000). A study of proof conceptions in algebra. Journal for Research in Mathematics Education, 31(4), 396-428.

[19] Mariotti, M. A. (2000). Introduction to proof: The mediation of a dynamic software environment. Educational Studies in Mathematic, 44 (1), 25-53.

[20] Balacheff, N. (1988). Aspects of proof in pupils' practice of school mathematics in D. Pimm, Mathematics, Teachers and Children. Hodder \& Stoughton, London. 216- 230.

[21] Öner, D. (2008). Supporting students' participation in authentic proof activities in computer supported collaborative learning (CSCL) environments. Computer-Supported Collaborative Learning, 3, 343-359.

[22] Stylianides, A. J. (2007a). Proof and proving in school mathematics. Journal for Research in Mathematics Education, 38 (3), 289-321.

[23] Ko, Y-Y. (2010). Mathematics teachers' conceptions of proof: implications for educational research. International Journal of Science and Mathematics Education, 8, 1109-1129. 
[24] Alibert, D., \& Thomas, M. (1991). Research on mathematical proof. In D. Tall (Ed.), Advanced mathematical thinking (pp. 215-230). The Netherlands: Kluwer.

[25] Stylianides, A. J. (2006). Proof and proving in school mathematics instruction. Paper presented at the Annual Meeting of the American Educational Research Association, San Francisco, CA, USA.

[26] Lampert, M. (1990). When the problem is not the question and the solution is not the answer: Mathematical knowing and teaching. American Educational Research Journal, 27 (1), 29-63.

[27] Maher, C., \& Martino, A. (1996). The development of the idea of mathematical proof: A 5-year case study. Journal for Research in Mathematics Education, 27, 194-214.

[28] Carpenter, T., \& Franke, M. (2001). Developing algebraic reasoning in the elementary school: Generalization and proof. In H. Chick, K. Stacey, J. Vincent \& J. Vincent (Eds.), Proceedings of the Twelfth International Commission on Mathematical Instruction (vol. 1, pp. 155-162), University of Melbourne, Melbourne.

[29] Harel, G., \& Sowder, L. (1998). Students' proof schemes: Results from exploratory studies. In E. Dubinsky, A. Schoenfeld, and J. Kaput (Eds.), Research on Collegiate Mathematics Education, III (pp.234-283). AMS.

[30] Coe, R., \& Ruthven, K. (1994). Proof practices and constructs of advanced mathematics students. British Educational Research Journal, 20, 41-53.

[31] Fischbein, E. (1982). Intuition and Proof. For The Learning of Mathematics, 3(2), 9-18.

[32] M.E.B. (2013). Ortaokul Matematik Dersi (5, 6, 7 ve 8. Sinıflar) Programı. Ankara: Milli Eğitim Basımevi.

[33] Stylianides, G. J., \& Stylianides, A. J. (2009). Facilitating the transition from empirical arguments to proof. Journal for Research in Mathematics Education, 40 (3).

[34] De Villiers, M. (1999). Rethinking proof with the geometers' sketchpad. Emeryville, CA: Key Curriculum.

[35] Bell, A. (1976). A study of pupils' proof-explanations in mathematical situations. Educational Studies in Mathematics, 7, 23-40.

[36] Miyazaki, M. (2000). Levels of proof in lower secondary school mathematics. Educational Studies in Mathematics, 41, 47-68.

[37] Weber, K. (2001). Student difficulty in constructing proofs: The need for strategic knowledge. Educational Studies in Mathematics, 48, 101-119.

[38] Stylianides, A. J. (2007b). Introducing young children to the role of assumptions in proving. Mathematical Thinking and Learning, 9(4), 361-385.
[39] Lawler, R. W. (1980). The progressive construction of mind. Cognitive Science, 5, 1-34.

[40] Bieda, K. (2010). Enacting proof in middle school mathematics: Challenges and opportunities. Journal for Research in Mathematics Education, 41, 351-382.

[41] Lester, F . K. (1980). A procedure for studying the cognitive processes used during problem solving. Journal for Experimental Education, 48, 323-327.

[42] Komatsu, K. (2010). Counter-examples for refinement of conjectures and proofs in primary school mathematics. Journal of Mathematical Behavior, 29, 1-10.

[43] Miles, B., \& Hubermam, A. M. (1994). Qualitative Data Analysis: An expended sourcebook (second edition). Newbury Park, CA: Sega.

[44] Dede, Y., \& Karakuş, F. (2014). A pedagogical perspective concerning the concept of mathematical proof: A theoretical study. Adryaman University Journal of Educational Sciences, 4 (2), 47-71.

[45] Raman, M. (2003). Key ideas: What are they and how can they help us understand how people view proof? Educational Studies in Mathematics, 52, 319-325.

[46] İskendeoğlu, T. (2010). Proof Schemes Used By Prerservice Mathematıcs Teachers And Their Ideas About Proof. [PhD Thesis] Karadeniz Technical University/Institue of Naturel \& Applied Sciences, Trabzon.

[47] Knuth, E.C., Chopin, J.M., \& Bieda, K.N. (2009). Proof: Examples and Beyond. Mathematics Teaching in the Middle School, 15 (4), 206-211.

[48] Cooper, J. L., Walkington, C. A., Williams, C. C., Akinsiku, O. A., Kalish, C. W., Ellis, A. B., \& Knuth, E. J. (2011). Adolescent Reasoning in Mathematics: Exploring Middle School Students Strategic Approaches in Empirical Justifications, In Proceedings of the 33rd Annual Conference of the Cognitive Science Society. Boston, MA., Retrieved on 17-June-2015 at URL: http://mindmodeling.org/cogsci2011/papers/0509/paper0509

[49] Knapp, J. (2005). Learning to prove in order to prove to learn. [online] : Retrieved on 17-June-2015 at URL: https://mathpost.asu.edu/ sjgm/issues/2005_spring/SJGM_k napp.pdf

[50] Edwards, B. S., \& Ward, M. B. (2004). Surprises from mathematics education research: Student (mis)use of mathematical definitions. The American Mathematical Monthly, 111, 411-424.

[51] Baker, D., \& Campbell, C. (2004). Fostering the development of mathematical thinking: Observations from a proofs course. Primus, 14 (4), 345-353.

[52] Burns, M. (1985). The role of questioning. Arithmetic Teacher, 32 (6), 14-17. 